\title{
La cultura del consumo a través de la investigación social: acontecimientos teórico-metodológicos
}

\author{
LAURA L. ORTIZ-NEGRÓN \\ Centro de Investigaciones Sociales \\ Universidad de Puerto Rico \\ llortiz@uprrp.edu
}

Recibido: 15.03 .2006

Aceptado: 20.11 .2006

En medio de la crisis paradigmática que ha atravesado el discurso de la ciencia en las últimas décadas, es oportuno compartir esta reflexión en torno a la empiria de la cultura del consumo, entendida como aquellas experiencias que permiten no sólo abordar el objeto de estudio sino pensar la investigación mis$\mathrm{ma}^{1}$. Se trata de pensar la investigación desde experiencias que si bien pueden quedar al margen de los resultados de un estudio son elementos que figuran el proceso de conocer. En este sentido, el consumo en tanto tema de estudio así como la técnica de la entrevista han sido las dos prácticas de investigación que han figurado estos acontecimientos teórico-metodológicos para pensar la investigación social como una experiencia contextualmente producida.

La investigación que he realizado sobre la economía del consumo en Puerto Rico es el terreno que me permite el abordaje de las relaciones «no científicas» entre la investigación y los sujetos de estudio ${ }^{2}$. Cuando se habla de relaciones

${ }^{1}$ La reapropiación de la palabra empiria en este trabajo se produce bajo dos registros contextuales. El primero alude indirectamente al legado del empiricista británico David Hume (siglo XVIII) en torno a la producción del conocimiento y sus límites. La experiencia del conocer como límite humano marca este primer registro. Segundo, si bien durante el transcurso del siglo XX se produjeron investigaciones y trabajos que trastocaban y sepultaban muchos de los postulados diáfanos y estables del discurso de la ciencia, ha sido durante las últimas décadas que los trances paradigmáticos han permitido repensar y producir la investigación y el posible conocimiento a nivel interdisciplinario o transdisciplinario y asumirla como una práctica intelectual falible. La empiria, desde estas perspectivas, se aborda en su sentido más clásico, aquella de la experiencia posible del conocimiento que va marcando el quehacer intelectual. Por lo que se advierte que no es una intervención sobre la microingeniería entre hipótesis, datos y análisis estadísticos que se exhiben como investigaciones rigurosas. Algunas referencias que apuntan y analizan esta crisis paradigmática son: Bachelard (1978), Estefanía (1998), Maturana y Varela (1995), Morin (1984), Prigogine y Stengers (1994), Schnitman (1994) y Mires (1996).

${ }^{2}$ Para efectos de este estudio la economía del consumo se define como aquella que comprende tanto el régimen de consumo y la cultura de consumo como partes de una economía más amplia, fuera de su entendido economicista tradicional. Este proyecto de investigación comprende un 
«no científicas», es una posición asumida desde un gesto postestructuralista mediante el cual no se pretende establecer un sistema interpretativo o modelo crítico integral ni coherente; sólo se intenta compartir el terreno de lo inestable y múltiple de la relación observadora y sujeto de estudio ${ }^{3}$. Y dentro de este gesto postestructuralista se produce a su vez un relato misceláneo que trasciende las fronteras disciplinarias ${ }^{4}$. El campo de las significaciones, el lenguaje y el texto fulminan así las fronteras de la teoría, el formalismo y la estructura llegando a lo que algunos estudiosos han llamado la literariedad (J. Culler, 1997), y cuya capacidad dialógica y argumentativa se presenta, a su vez, como una práctica inciertamente sostenida en el proceso de investigación (P. de Man, 1971).

La experiencia de investigación a través de las entrevistas que he sostenido con consumidoras y consumidores es la que permite elaborar esta discusión sobre los trastoques teórico-metodológicos que se producen y se presentan como acontecimientos en el proceso de la labor investigativa y la reflexión intelectual.

Un primer trastoque apunta al asunto del «género» y la técnica de investigación propiamente, en esta caso la entrevista. En una entrevista se habla y se conversa; se hacen preguntas y se contestan las mismas, también hay silencios. Está presente la investigadora, autoridad situada, y la entrevistada, que debe someterse a la autoridad de ésta. Pero hay que recordar que la ideología y el imaginario del consumo se ha vinculado por mucho tiempo a un asunto de mujeres. Si bien esta ideología e imaginario está en disputa, como se expone más adelante, la misma se presenta como estrategia comunicativa entre la entrevistada y la investigadora. La entrevistada y la investigadora entran en un juego de «complicidad comprensiva» en el que la primera espera que su respuesta sobre su pasión por el ir de compras sea una experiencia similar para la mujer investigado-

abordaje interdisciplinario del consumo como fenómeno contemporáneo que define y transforma prácticas, roles, relaciones y significados socioculturales en Puerto Rico desde un contexto global. El consumo se produce como parte de un imaginario social que fluye a través de espacios mediáticos, comerciales, económicos y políticos, y cuya reapropiación por los consumidores(as) define su producción como orden simbólico y significante de la vida en sociedad y del cuidado de sí por cada sujeto. Este estudio ha comprendido una metodología cuyas fases y técnicas de investigación han sido muy variadas: la administración de un cuestionario a los visitantes de los diversos centros comerciales en Puerto Rico, la realización de entrevistas estructuradas a consumidores(as), la filmación de vídeos en los centros comerciales y fuentes documentales diversas. A través de esta investigación se presenta una mirada sociocultural a: los entendidos conceptuales del consumo; el financiamiento de la esfera del consumo; la dimensión semiotica y urbana del establecimiento comercial; las características y subjetividades de los consumidores(as) y; la relación de los consumidores(as) con los objetos de consumo y el espacio del mall. Algunos de los resultados de este proyecto de investigación son: un vídeo digital (Ortiz-Negrón, 2005), varios artículos (Ortiz-Negrón, 2004a, 2004b y 2006a) y un capítulo en libro (Ortiz-Negrón, 2006b).

${ }^{3}$ Una de las lecturas postcartesianas supone la inclusión del sujeto en el discurso de la ciencia y sus axiomas, no para ser estudiado como sujeto morfológico, sino para explicitar la condición relacional y situacional del conocimiento en la medida que el sujeto y el objeto de estudio se implican uno al otro.

${ }^{4}$ Algunos de los trabajos de Roland Barthes como El imperio de los signos y Cámara lúcida ya marcan la implosión de las fronteras disciplinarias. 
ra. Cuando se le pregunta a una de las entrevistadas sobre los beneficios que le produce ir de compras, ésta responde «como tú sabes, a todas nosotras nos encanta ir de shopping, muchacha el shopping nos eleva de verdad». Y luego más adelante, la entrevistada añade «tú no te has probado las panty hose estas, de Colombia, yo las mandé a buscar y la verdad es que funciona, me levantan las nalgas». Se le preguntó «¿cuáles son esas medias milagrosas?, yo no las conozco», a lo que ella responde «claro que tienes que saber de qué te hablo». La entrevistada suspende en ese momento la posibilidad de brindar un nuevo conocimiento desde el sujeto de estudio, pero puede que corrobore lo que ya existe en la experiencia o el imaginario de la investigadora. Lo particular de su confesión tiene un efecto de nivelación que puede permitir que ella continúe hablando porque le está hablando a otra mujer. La investigadora a su vez juega con esa posibilidad porque la voz de la entrevistada mantiene esta significación. En este contexto la investidura de investigadora no desaparece sino que se fricciona con las otras investiduras de «ser mujer» y consumidora. Se da una transformación a través del lenguaje del que habla y del que escucha, y de sus realidades. Si bien la ideología es la representación del mundo y del modo de vida a través del consumo, la misma se utiliza en el proceso de la entrevista como posible imaginario compartido; se reinventa esa representación a través de un estado subjetivo del consumo socializado por las mujeres. Es decir, el concepto de ideología se disuelve en el concepto de imaginario a través de la relación etnográfica entre la investigadora y la entrevistada. Este con-texto comunicativo, apunta a lo que James Clifford puntualiza sobre la etnografía como espacio retórico (J. Clifford, 1986). Un texto retórico apunta a la falta de una verdad, finalidad y una interpretación completa del tema bajo estudio. Incluso, lo retórico se presenta como una dislocación y una reinvención de lo real. Dado el hecho de que en un proceso etnográfico o investigativo en las ciencias humanas intervienen asuntos de poder y cultura -ideologías, discursos e imaginarios- el mismo se produce inevitablemente como una parcialidad seria. Es decir, el rigor no debe estar reñido con esta parcialidad en el conocimiento.

Un segundo trastoque se vincula al lenguaje y su producción temporal. El lenguaje hablado de la entrevista tiene una significación temporal que se trastoca con la palabra escrita. Durante la entrevista, la voz o la parole toman una supremacía aparente no sólo sobre lo escrito, sino que traza lo contingente de una comunicación nunca actual. Cuando se transcribe la entrevista y se examina el texto escrito se produce otra significación; cómo recordar cada detalle de la entrevista, la risa, la tensión, el humor de la mujer entrevistada, sus silencios y disgresiones. Se trata de lo que se escapa. La producción temporal de la comunicación apunta al menos hacia otros dos acontecimientos. Un primer acontecimiento apunta a que se produce un conocimiento de declaración, reserva y recelo a través de la comunicación, donde el entrevistado o entrevistada informa lo que quiere o puede como un acto siempre incompleto. Un segundo acontecimiento presenta otro problema, cómo recuperar los significados del texto etnográfico cuando la entrevista — texto hablado - pasa a ser transcripción, texto escrito. El 
tiempo diferido entre investigar, analizar y escribir sobre lo conversado marca la dificultad en una transcripción. La transcripción guarda siempre lo que se escapa del conocimiento. De este modo, la escritura deviene como error no sólo porque la lectura e interpretación reside en la arbitrariedad de la autora o porque la palabra escrita se constituye en traición, sino como nos susurra Bataille, «nunca el conocimiento es soberano, para ser soberano, debería tener lugar en el instante» (G. Bataille, 1996: 69). Habría que asumir de manera inescapable que nuestro conocimiento es la del objetivo y la del futuro y que el instante siempre se nos escapa, este es el problema de horario. La destrucción del futuro por los entrevistados y entrevistadas se da en esta tensión y mediación del horario. Y el trabajo del investigador(a) por ende tiene este problema de horario.

Un tercer acontecimiento está vinculado a la relación entre las nociones de «exotismo», «otredad» y «lo exótico» no sólo en la relación con el sujeto de estudio, sino con el propio tema de investigación. Para Michel Leiris (G. BrinkerGabler, 1995), el «exotismo» es la experiencia con la otredad. Lo «exótico» es la distorsión del Otro como degradación y objeto de proyección (Brinkler-Gabler, 1995). Cuando se habla del consumo como tema investigativo, de inmediato el sentido común o la ideología que asalta es que «los puertorriqueños compran mucho o que siempre están comprando», sobretodo la pregunta que emerge es, «¿y de dónde sacan tanto dinero?» Además se comenta «como los centros comerciales siempre están llenos cuando la gente no tiene dinero y la economía está tan mala». El puertorriqueño es exótico porque porta un misterio y una seducción por el consumo de modo irracional a lo que hay que buscarle una racionalidad o un origen. Es este sentido ideológico el que permite que al estudiar el consumo se explore y se logre una intervención comunicativa que delate este «síndrome». Como parte de las entrevistas realizadas durante esta investigación, se le preguntó a esta consumidora lo siguiente:

¿Qué significa para ti ir de compras?

«Tener el dinero para ir a un lugar para buscar ciertas cosas que necesito, es necesidad y cuando consigo lo que busco pues me da satisfacción, no hay disfrute, es una obligación»

¿Qué alegrías te produce el ir de compras?

«Si, yo soy una persona que no soy materialista y me he visto envuelta en el concepto de... consumir, cobro hoy y me compro algo, pero esas cosas que compro son para las primeras semanas, pero ya al mes ni lo uso.

¿Qué beneficios te produce el ir de compras?

«Es algo como metafórico, cuando yo voy de compras para mí es buscando algo que sea especial que no lo tenga todo el mundo y ese es el beneficio, la distinción".

A través de este espacio textual, si bien el consumo pierde su aureola de fuente de placer y donde lo especial del consumo desaparece para constituirse en un tarea más de la vida contemporánea, a otro nivel se recupera como algo que tiene que negarse como actividad literal y racional, para dar cuenta de su capa- 
cidad connotativa; lo misterioso del consumo es que puede brindar algo especial, en este caso, distinción. De manera similar, también la idea de necesidad vinculada a satisfacer funciones básicas de reproducción se elastiza cuando una de mis entrevistadas me indica que ir de compras para ella «es una necesidad, lo primero en comprar comida, dos para comprar cosas que se necesitan y tercero para comprarme cosas para mí, para sentirme bien». Los efectos textuales de este proceso comunicativo en la investigación son así de móviles y heterogéneos. El sujeto y su texto se produce no como individualidad contradictoria, sino como una producción discursiva llena de intertextualidad, lo que Kristeva define como una intertransposición de sistemas de signos (J. Kristeva, 1990). Aquí una imbricación de significaciones en la cual no hay misterio ante el fenómeno del consumo y a su vez, es lo que permite la obtención de algo especial. También se da un proceso de racionalización del consumo cuando uno de los entrevistados indica «bueno, los dueños de los malls son gente rica y junto con los grandes de la iglesia inauguran las expansiones de estos centros comerciales, usted los ve cortando la cinta, y después salen en la televisión. Eso quiere decir que todo esto del consumo es legítimo». Estas respuestas apuntan a que el consumo se produce como experiencia fuera de todo exotismo; es sobretodo una forma de racionalización y sentido del mundo exterior.

¿Qué es lo real, lo original, lo esencial de la mercancía, de la conciencia, o del sujeto? ${ }^{5}$ Aún cuando el consumo es el principio que rige la economía fordista y posfordista ${ }^{6}$ a nivel global, los sujetos se reapropian de esa economía y trascienden este imaginario económico alterando y resignificando su relaciones y subjetividades; re-crean nuevas formas de vida social. Las relaciones entre sujetos y objetos se transforman en dominios de agencia en los cuales se materializan fantasías, afirmaciones y otros significados culturales ${ }^{7}$.

A otro nivel del proceso de investigación y la labor etnográfica, se recupera un cierto sentido de «exotismo» cuando uno de los entrevistados conversa sobre todo lo que tiene y su modo de vida. Éste tiene 37 años de edad, sus ingresos son $\$ 2,700.00$ mensuales, tiene dos guaguas $4 \times 4$, un jet-ski, un four track, paga hipoteca y tiene 8 hijos de matrimonios anteriores. Ahora está casado y su pareja tiene una hija de 13 años. A través de la entrevista este consumidor va expresando lo que compra todos los días, a lo que añade que eso es parte de su per-

5 Algunas de las críticas al concepto de ideología como falsa conciencia y al concepto de enajenación se recogen en los trabajos de Daniel Miller (1991) y en Douglas Kellner (1983).

6 Veánse trabajos en torno al fordismo y posfordismo en: Harvey (1989), Krishan Kumar (1995), Alain Lipietz (1987) y Benjamin Coriat (1993).

7 Ver la ponencia Consumption: Shopping Through Theory en el portal de mi investigación cuya dirección es http://www.hypercon.rrp.upredu y el artículo de mi autoria, «Exorcizando el fetichismo finicesular: reflexiones en tomo al consumo», en bordes, Núm. 9. También desde la sociología y antropología clásica están los trabajos de Georg Simmel (1978) y de Marcel Mauss (1976), entre otros. A nivel más contemporáneo están los trabajos de Jean Baudrillard (1981, 1996, 1998, 1998, 1999); Daniel Miller (1991, 1998), McCracken (1990), Appadurai (1986), Slater (1997), Ewen (1988), Nava (1992), Douglas e Isherwood (1996), Falk y Campbell (1997), Featherstone (1991) y Clarke, Doel y Housiaux (2003). 
sona y de su vida. Cuando se le preguntó cuán importante era para él el ir de compras, éste contesta lo siguiente:

es $100 \%$ importante, porque a mi me gusta estar al día. Para mi compañera también, ella tiene que estar a la moda e ir diferente todos los días al trabajo y ahora la nena también, tiene un reloj diferente para cada día de la escuela ella se combina la correa con los zapatos y el reloj, tiene 13 años. Para Puerto Rico yo he observado que siempre hay gente que caminan todas las tiendas y no compran nada, gente que sale a relajarse en las tiendas, uno se olvida del mundo exterior, se olvidan las cuentas.

Luego se le pregunt 6, ¿sientes que eres parte igual a la mayoria de los consumidores? Y contestó, «Yo me siento que voy más allá, porque yo me estoy poniendo update». ¿Qué puedo interpretar? ... La capacidad reflexiva del trabajo intelectual es lo que da la vida. En su trabajo $L a$ voluntad de poder, Nietzsche nos recuerda que «La verdad es el tipo de error sin el cual una cierta especie de ser vivo no puede vivir» ( $F$. Nietzsche, 1968, traducción mía). También se trata de la responsabilidad con la historia del pensamiento en la medida que las reflexiones producidas labren aquello que parece como familiar, en algo distante e incierto. Puede ser que se entre en una operación de exotismo y exorcismo de las categorías con las cuales se producen nuestros análisis. Lo que se explore y se busque contestar a través de la labor intelectual implica un escrutinio constante entre lo que se interroga y lo que se suple.

Un cuarto trastoque o acontecimiento que quisiera abordar está relacionado a una interrogante desde la posición como intelectual. Este acontecimiento invita a discutir o dejar planteado lo ético a través y más allá de la producción del conocimiento situado y contingente. Se trata de cómo hilar la solvencia y competencia de los paradigmas y temas de estudio seleccionados, ante un estado muy hostil del mundo y de la vida cotidiana. A partir de este escenario se puede producir un sentimiento de ahogo, impotencia y tristeza ante el requerimiento automatizado de seguir trabajando y no poder parar. Ese estado de producción y vida va acompañado de muchas pérdidas. No sólo es el agravio y desplazamiento de la intelectualidad, sino la pérdida de la vida misma. Parecería que el concepto de razón cínica elaborado por el filósofo Peter Sloterdijk, puede ser un posible camino a la pregunta reflexiva que éste se hace, ¿dónde estamos? ¿Entre la producción, la destrucción y la depresión? Sloterdijk afirma que el descontento de nuestra cultura se presenta en este momento histórico como un cinismo difuso. Este cinismo es una falsa conciencia ilustrada. El Iluminismo así como la modernidad fue nuestro espacio de formación y vida, pero su propia producción nos llevó a la miseria ${ }^{8}$. No sólo se trata de una negatividad termodinámica como efecto científico y económico, sino de una regulación. Ante la razón instrumental y la razón cínica, es un estar desnudos pero en privado. Zygmunt Bau-

${ }^{8}$ La destrucción del medio ambiente ha sido un ejemplo dramático de esta condición del mundo. 
man, en otro registro, comenta que ante el estado del mundo hay que diseñar los trazos de nuevas experiencias humanas. ¿Existe la posibilidad de reinventarnos? o terminaremos como Gelsonima, el personaje de La Strada de Federico Fellini (1954), la joven entregada al hombre de circo, y que en su angustia por falta de no estar «en casa» y por falta de amor, marca su precaria y humillante sobrevivencia frente a la continuidad de la vida y alegría de los otros. Sobre este particular, Bauman argumenta que,

Cada sitio concebible que uno ocupe en un momento dado, o el que pueda ocupar en otro, está indefectiblemente dentro del mundo, y destinado a permanecer en su interior para siempre. Se entienda por esto último lo que se entienda. En este mundo agotado, somos todos residentes permanentes, sin otro sitio adonde ir (Z. Bauman, 2002: 22).

Se trata, de que al desarmar nuestros marcos conceptuales y en duelo con ellos, el conocimiento debe apostar a la posibilidad del pensar en su sentido más vital.

\section{BIBLIOGRAFÍA}

Appadurai, ed. (1986): The Social Life of Things Commodities in Cultural Perspective, Cambridge: Cambridge University Press.

BACHELARD, Gastón (1978): La formación del espíritu científico: contribución a un psicoanálisis del conocimiento objetivo. Buenos Aires: Siglo XXI.

Batallle, Georges (1996): Lo que entiendo por soberanía. Traducido por Pilar Sánchez Orozco y Antonio Campillo. Barcelona: Paidós.

BaUdRILlard, J. (1981): For a Critique of the Political Economy of the Sign, St. Louis: Telos Press.

BaudRILlaRd, J. (1990): Culture and Consumption New Approaches to the Symbolic Character of Consumer Goods and Activities. Bloomington-Indianapolis: Indiana University Press.

- (1991): Material Culture and Mass Consumption, Oxford: Blackwell.

- (1996): The System of Objects, London-New York: Verso.

- (1998): The Consumer Society - Myths and Structures, London-California-New Delhi: Sage Publications.

- (1999): Revenge of the Crystal Selected Writings on the Modern Object and Its Destiny: 1968-1983. London: Pluto Press; Daniel Miller.

Bauman, Zygmunt (2004): La sociedad sitiada. Argentina: Fondo de Cultura Económica.

BRINKLER-Gabler, G. (ed.) (1995): Encountering the Other(s) Studies in Literature, History, and Culture. Albany: State University of New York.

Clarke, Marcus A. Doel y Kate M. L. HousiauX (2003): The Consumer Reader. London-New York: Routledge.

ClifFord, James y George E. MARcus, eds. (1986): Writing Culture - The Poetics and Politics of Ethnography. Berkeley, Los Angeles \& London: The California University Press. 
CULLER, Jonathan (1997): Literary Theory: A Very Short Introduction. Oxford: Oxford University Press.

David Harvey (1989): The Condition of Postmodernity. Cambridge: Cambridge University Press.

DE MAN, Paul (1971): «The Rethoric of Blindness: Jacques Derrida's Reading of Rousseau» en Blindness and Insight. Essays in the Rethoric of Contemporary Criticism. New York: Oxford University Press.

DOUGLAS, M. y BARON ISHERWOOD (1996): The World of Goods Towards an Anthropology of Consumption. London-New York: Routledge;

EsteFANíA, Joaquín (1998): Contra el pensamiento único. Madrid: Taurus.

EWEN (1988): All Consuming Images The Politics of Style in Contemporary Culture. New York: Basic Books.

FALK, P. y C. CAMPBELL, eds. (1997): The Shopping Experience, London: Sage.

Featherstone (1991): Consumer Culture and Postmodernism. London: Sage.

Gauss, M. (1976): The Gift. New York: Norton.

Kellner, D. (1983): «Critical Theory, Commodities and the Consumer Society», Theory, Culture \& Society, I(3).

Krishan Kumar (1995): From Post-Industrial to Post-Modern Society New Theories of the Contemporary World, Oxford: Blackwell.

KrISTEVA, Julia. (1990): Revolution in Poetic Language. Columbia University Press, LIPIETZ (1987): Mirages and Miracles: the Crises of Global Fordism, London: Verso.

Maturana, Humberto y VAREla, Francisco (1995) De máquinas y seres vivos: autopoiesis: la organización de lo vivo. Santiago de Chile: Editorial Universitaria.

MCCRACKEN (1990): Culture and Consumption New Approaches to the Symbolic Character of Consumer Goods and Activities. Bloomington-Indianapolis: Indiana University Press.

MiLlaR, D. (1991): Material Culture and Mass Consumption. Oxford: Blackwell.

- (1998): A Theory of Shopping. New York: Cornell University Press.

MIRES, Fernando (1996): La revolución que nadie soñó o la otra posmodernidad. Venezuela: Nueva Sociedad.

MORIN, Edgar (1984): Ciencia con conciencia. Barcelona: Anthropos.

NAVA (1992): Changing Cultures Feminism, Youth and Consumerism. London: Sage.

NiETzSCHE, Friedrich (1968): The Will to Power. Walter Kaufman y Hollingdale, traductores. New York: Vintage Books.

ORTIZ-NEGRÓN, L. (2004a): «Criogenización de lo real o la topología de lo irreal a través del mall». Revista filos, (1).

ORTIZ-NEGRÓN, L (2004b): «De que callada manera se me acerca usted sonriendo: reflexiones en torno al consumo». Revista Teknokultura, (4).

ORTIZ-NEGRON, L (2005): Arcadas de las estaciones 20-21: Visiones de los centros comerciales en Puerto Rico Universidad de Puerto Rico, Recinto de Río Piedras: Centro de Investigaciones Sociales. [vídeo].

ORTZZ-NEGRÓN, L (2006a): «Modernity-Postmodernity in Puerto Rico: Consumer Culture and Paradigmatic Crisis», en International Journal of the Interdisciplinary Social Sciences. Australia: Common Ground Publishers. Vol. 1, 1-10.

OrTiZ-Negrón, L (2006b): «Space Out of Place: Consumer Culture in Puerto Rico» en Negrón Muntaner, Frances (Ed.). None of the Above: Puerto Ricans in the Global Era. NY: Palgrave Macmillan. Capítulo 3, 39-50. 2006. 
PRIGOGINE, Ilya y STENGERS, Isabelle (1994): La nueva alianza: metamorfosis de la ciencia. Madrid: Alianza Editorial

Schnitman, Dora Fried (1994): Nuevos paradigmas, cultura y subjetividad. Buenos Aires: Paidós.

Simmel, G. (1978): The Philosophy of Money. London: Routledge.

SLATER (1997): Consumer Culture and Modernity. Cambridge: Polity Press.

SLOTERDIJK, Peter (1987): Critique of Cynical Reason. Minneapolis: University of Minnesota Press.

CORIAT, B. (1993) El taller y el robot-Ensayos sobre el fordismo y la producción en masa en la era de la electrónica. España: XXI. 


\title{
RESUMEN
}

A partir de la investigación sobre la cultura del consumo en Puerto Rico, y de ciertas experiencias del trabajo de campo, particularmente, la entrevista como herramienta etnográfica, se esbozan algunas reflexiones teórico-metodológicas que dislocan los entendidos dominantes del conocimiento y la investigación social. Estas reflexiones comprenden un abordaje analítico y argumentativo desde diversas tradiciones post-estructuralistas y debates contemporáneos sobre lo social. Asuntos vinculados a género, enunciaciones retóricas, a la otredad y la ética son algunos de los temas analizados en este ensayo.

\section{PALABRAS CLAVE}

Consumo, cultura, investigación social, retórica.

\begin{abstract}
It is on the basis of research conducted on consumer culture in Puerto Rico and fieldwork experiences, particularly, the interview as an ethnographic tool, that methological-theoretical reflections are presented which dislocate dominant understandings of knowledge and social research. These reflections are based on an analytical and argumentative approach issuing from diverse post-structuralist traditions and contemporary debates on the social. Issues related to gender, rhetorical enunciations, otherness and ethics are some of the topics analyzed in this essay.
\end{abstract}

\section{KEYWORDS}

Consumption, culture, social research, rhetoric. 